\title{
GC-MS analysis of Phytocomponents in the Methanol Extract of Premna latifolia Roxb
}

\author{
Rajesh Kumar, Brijesh Kumar*, Ashutosh Kumar, Ajay Kumar, Manish Singh
}

Rajesh Kumar,

Brijesh Kumar*, Ashutosh Kumar, Ajay Kumar, Manish Singh

Department of Pharmacology, Institute of Medical Sciences, Banaras Hindu University Varanasi, Uttar Pradesh, INDIA.

\section{Correspondence}

\section{Prof. Brijesh Kumar}

Department of Pharmacology, Institute of Medical Sciences, Banaras Hindu University, Varanasi-221005,

Uttar Pradesh, INDIA.

Email id: asthwal@rediffmail.com

\section{History}

- Submission Date: 17-08-2021;

- Review completed: 02-09-2021;

- Accepted Date: 15-10-2021

\section{DOI : 10.5530/pres.14.1.4}

Article Available online http://www.phcogres.com

\section{Copyright}

(c) 2022 Phcog.Net. This is an openaccess article distributed under the terms of the Creative Commons Attribution 4.0 International license.

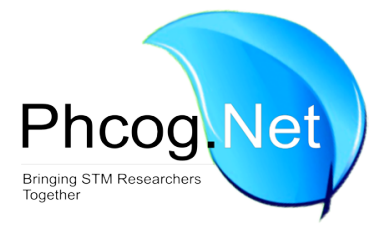

\begin{abstract}
Background: According to existing literature, the genus Premna has a variety of biologically active secondary metabolites, but there are few findings on phytochemical screening of P. latifolia Roxb. Methanolic leaves extract. Objectives: Phytochemical screening of methanolic leaves extract of $P$. latifolia was proposed for this study. Materials and Methods: UV-chamber, HPTLC instrument (CAMAG TLC Scanner), and GC-MS instrument (Perkin-Elmer GC- Clarus) were used to analyse methanolic leaves extract of $P$. latifolia. To compare the peaks of components on chromatograms, the NIST library was employed. Results: The current study used GC-MS to identify probable chemical components of $P$. latifolia. The GC-MS analysis and NIST library comparison revealed that the methanolic extract of $P$. latifolia contained mainly Squalene (13.57 percent), Ergosta-5, 7, 9 (11), 22-tetraen-3-ol, (3. beta, 22E)-(0.15 percent), Stigmasterol (3.73 percent), gamma-Sitosterol (10.13 percent), Lupeol (0.33), beta-Amyrin (2.27 percent), alpha-Amyrin (2.05 percent), gamma-Sitostenone (0.35 percent), Ursolic aldehyde (1.01 percent) and Betulin (0.72 percent). The biological actions of the majority of the identified components have been reported. While scientific evidence of gamma-sitostenone's biological function is still not available. Conclusion: According to the findings, P. latifolia contains a variety of biologically active components, the majority of which are tri-terpenoids and phytosterols.
\end{abstract}

Key words: Premna latifolia, GC-MS analysis, Phytocomponents TLC,HPTLC, Methanolic leaves extract.

\section{INTRODUCTION}

Plants provide over $70 \%$ of the strong medications, so they can be regarded a significant source of drugs in various countries. ${ }^{[1]}$ People have been getting drugs from plants since the dawn of humanity. ${ }^{[2]}$ As a result, herbs are well-known for their traditional uses as folk medicines. ${ }^{[3]}$ Phytochemical screening is a crucial step in determining the active pharmacological components. ${ }^{[4]}$ Preliminary screening procedures for plant extracts have been suggested as a way to identify their beneficial pharmacological components. ${ }^{[5]}$ These pharmacological active components lead to the development of novel drug moieties using in vitro and in vivo approaches. ${ }^{[6]}$

Premna is a genus of more than 40 species in the verbinaceceae family ${ }^{[7]}$ Premna latifolia is a North Indian plant that is best known for its anti-inflammatory and anti-allergic properties in traditional medicine. ${ }^{[8]}$ However, no scientific evidence exists to date that it has a powerful anti-pathological effect. Premna's diverse biological activities can be attributed to the presence of alkaloids, flavonoids, tannins, resins, enzymes, and physiologically important secondary metabolites in various species. ${ }^{[9]}$ According to the available data, there haven't been many reports on $P$. latifolia's phytochemical components or biological activity. The goal of this study was to use a sophisticated instrument called GC-MS to look into the biological active components of $P$. latifolia.

\section{MATERIALS AND METHODS}

Plant material

Dr. Y. S. Parmar University of Horticulture and Forestry, Nouni, Himachal Pradesh, identified P. latifolia gathered from Dol Lasawa, Jhandutta, Bilaspur District, and Himachal Pradesh, India. A herbarium sheet of the same plant sample was sent to the Department using UHF-herbarium Field Book No. 12436.

\section{Preparation of extract}

To avoid degradation, the P. latifolia plant material was dried in the shade and the size was reduced with a grinder. The extraction procedure with methanol (95 percent) was used after a 7-day cold maceration. Whatman No. 41 filter paper was used to filter the retrieved material. The filtrate was dried with liquid nitrogen in a nitrogen evaporator at $30^{\circ} \mathrm{C}$. For subsequent examination, the dried methanol extract of $P$. latifolia (MEPL) was kept in the refrigerator at $2-8^{\circ} \mathrm{C}$. 


\section{Partition Chromatography}

By using $150 \mathrm{ml}$ each of petroleum ether (PE), ethyl acetate (EA), and water (AQ), the MEPL main extract was separated into three fractions: PLPE, PLEA, and PLAQ. At room temperature, the separated fractions were dried.

\section{Thin layer chromatography (TLC)}

Using a solvent system, TLC was done on pre-coated plates of silica gel $60 \mathrm{~F}_{254}$ (Merck) (5 percent Ethyl Acetate in Hexane). Spraying a combination of Anisaldehyde sulphate on a chromatographic plate separated by running reference compounds was used to identify the phyto-constituents, which were then scanned at (short wave - $254 \mathrm{~nm}$ and long wave $-366 \mathrm{~nm}$ ) and spotted. The retention factor $\left(\mathrm{R}_{F}\right)$ values were calculated using the compounds collected on the TLC plate.

\section{High Pressure Thin Layer Chromatography (HPTLC)}

TLC aluminium sheets silica gel $60 \mathrm{~F}_{254}$ (Merck) were used for HPTLC. The mobile phase was Toluene: Chloroform: ethyl acetate (4:4:1) and the sample injection volume was $30 \mu \mathrm{l}$. The CAMAG TLC Scanner was used to analyse the PLPE, PLEA, and PLAQ fractions using the CATS Planer Chromatography Manager Software (2.01.02). Scan wavelengths were $254 \mathrm{~nm}$ and $366 \mathrm{~nm}$. The retention factor and area percent of the individual bands on the TLC plate were computed after they were analysed.

\section{GC-MS analysis}

The PLEA fraction generated after partition chromatography was subjected to GC-MS analysis. Instrument conditions for the GC programme include Ion source temperature $2200^{\circ} \mathrm{C}$, Interface temperature $2600^{\circ} \mathrm{C}$, Flow control mode-Linear velocity, Pressure-90.4kPa, solvent cut time $2.5 \mathrm{~min}$, Detector gain mode-Relative, Threshold-1000, and for the MS table, start time $3.0 \mathrm{~min}$, end time $39.98 \mathrm{~min}$, ACQ mode- Scan, Event time $0.20 \mathrm{sec}$, Scan Speed 3333, and solvent cut time $2.5 \mathrm{~min}$. The settings of start $\mathrm{m} / z 40.00$ and finish time $\mathrm{m} / z 650.00$ were used.

\section{RESULTS AND DISCUSSION}

The MEPL extract ( $10 \mathrm{~g}$ ) was separated using a separating funnel and various solvents based on polarity, yielding three different fractions (PLPE, PLEA, and PLAQ), which were then dried at room temperature. The yields were determined to be 1.8, 2.4, and 1.6 percent, respectively. When run through the TLC plate using the solvent system, the TLC profile clearly demonstrates the presence of distinct phyto-constituents determined on the basis of colour density in three different fractions (PLPE, PLEA, and PLAQ). When spotted on a TLC plate following derivatization, the $\mathrm{R}_{f}$ values found in three fractions were $0.57,0.56$, and 0.46 , respectively as shown in Figure 1. After partition chromatography, the three fractions were used for a 51 injection on an HPTLC device. The results are depicted in Figures 2 and 3, which clearly demonstrate the various peaks, their $\mathrm{R}_{f}$ values, and the area percentage of each peak. In comparison to PLAQ, PLPE and PLEA have the most peaks. Some peaks were more evident following derivetization and when seen at a wavelength of $366 \mathrm{~nm}$. The peak's intensity was clearly reflected by the area percentage.

GC-MS Spectra analysis of the PLEA indicated the existence of various phytochemical components (Figures 4 and 5). By comparing their mass spectra to those in the NIST libraries, (Table 1) the 10 phytocompounds were identified and characterised. Table 2 lists the various phytocomponents as well as their biological activities. Squalene (13.57 percent), Ergosta-5, 7, 9 (11), 22-tetraen-3-ol, (3. beta, 22E)-(0.15 percent), Stigmasterol (3.73 percent), gamma-Sitosterol (10.13 percent), Lupeol (0.33), beta-Amyrin (2.27 percent), alpha-Amyrin (2.05 percent), gamma-Sitostenone (0.35 percent), Ursolic aldehyde (1.01 percent) and

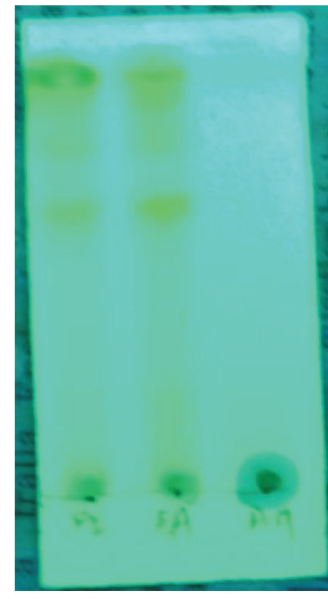

A

Figure 1: Thin Layer Chromatography. A (Before derivetization), $B$ (After derivetization), spotted at $254 \mathrm{~nm}$ and $366 \mathrm{~nm}$ )

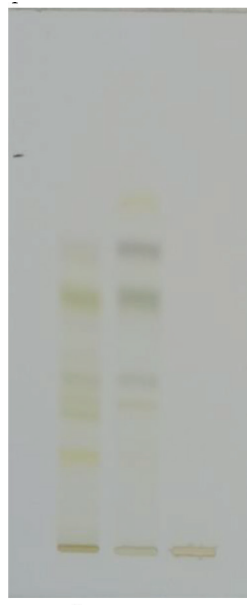

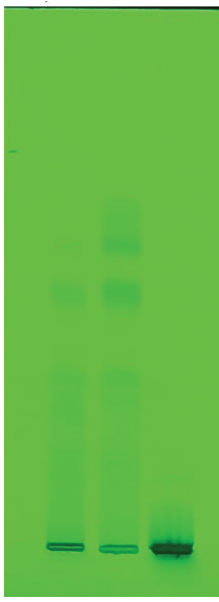

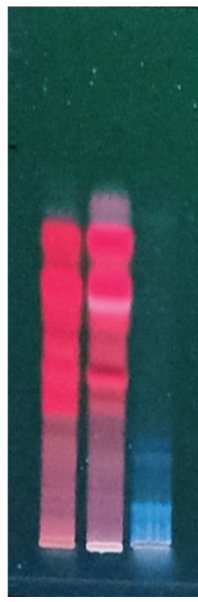

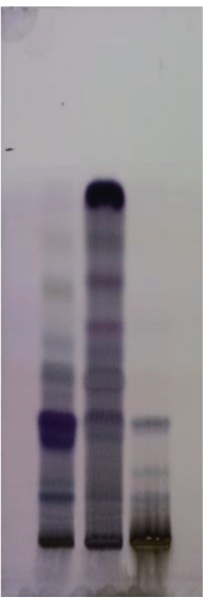

D
Figure 2: High Pressure Thin Layer Chromatography: $A$ (Visible light), B (254 nm, UV light), C (366 nm, UV light) and D (366 nm, Post Derivetization, UV light)

Betulin (0.72 percent) were the most prevailing compounds (Figure 6). Squalene is a triterpene that has been shown to have anticancer properties. ${ }^{[10]}$ It also hydrates the skin by acting as an emollient and antioxidant. ${ }^{[11]}$ Triterpines are phenolic compounds found in the latex of some plants that function as secondary metabolites in the defence against infections that cause human and animal diseases. ${ }^{[12]}$ Stigmasterol is a steroidal compound with anti-osteoarthritic activity, which is due to properties of their functional groups and their aqueous solubility. ${ }^{[13]}$ Ergosta-5, 7, 9 (11), 22-tetraen-3-ol, (3. beta. 22E) - has been justified as a phytosterol for its antitumor activity. ${ }^{[14]}$ Lupeol is a triterpenoid compound that has been used to treat prostate and skin cancers as well as an anti-inflammatory drug. ${ }^{[15]}$ Beta amyrin and alpha amyrin are two compounds that exhibit analgesic, anti-inflammatory, anticonvulsant, antidepressive, gastroprotective, hepatoprotective, antipancreatitic, anticholytic, antihyperglycemic, and hypolipidemic properties. ${ }^{[16]}$ Gamma.-Sitostenone, on the other hand, has no known activity. Ursolic aldehyde is a triterpenoid that has anti-glycative properties. ${ }^{[17]}$ Finally, Betulin demonstrates antimalarial, anti-inflammatory, and antifungal properties. ${ }^{[18]}$ 

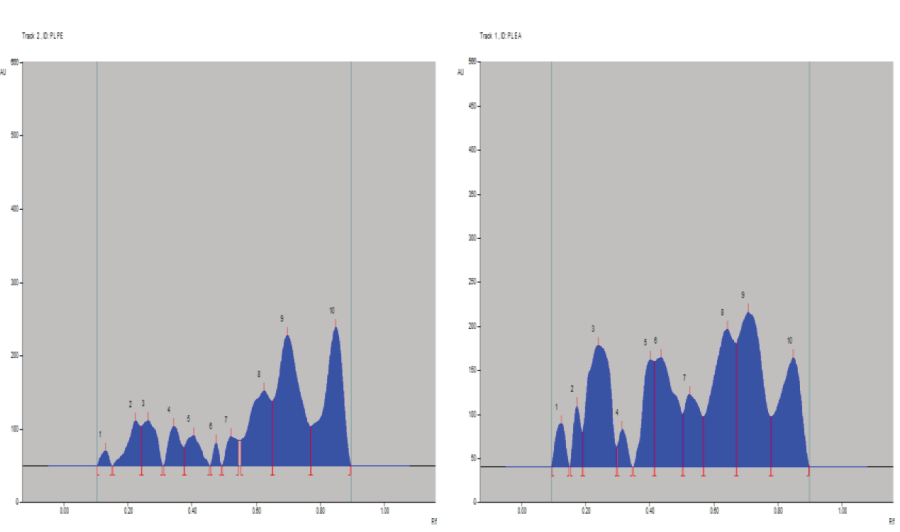

A

B

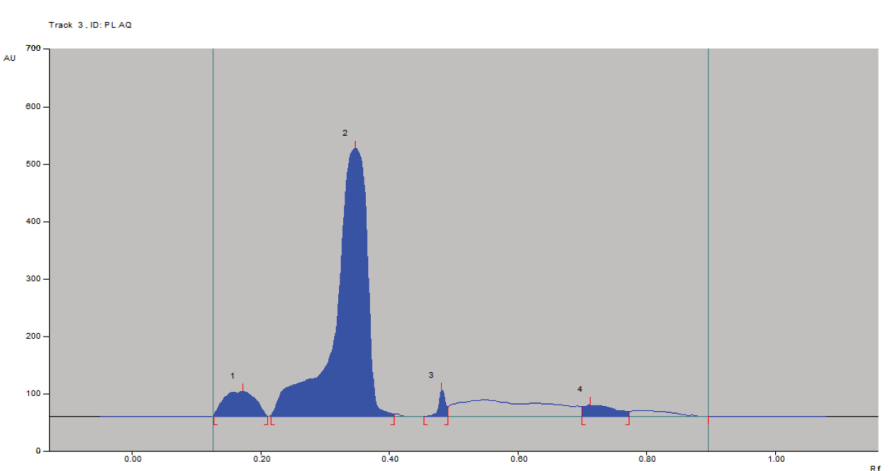

C

Figure 3: HPTLC Peaks of Different Phytoconstituents: A (PLPE), B (PLEA) and $C$ (PLAQ).

PLPE (Premna latifolia, petroleum ether fraction), PLEA (Premna latifolia, ethyl acetate fraction) and PLAQ Premna latifolia, aqueous fraction)

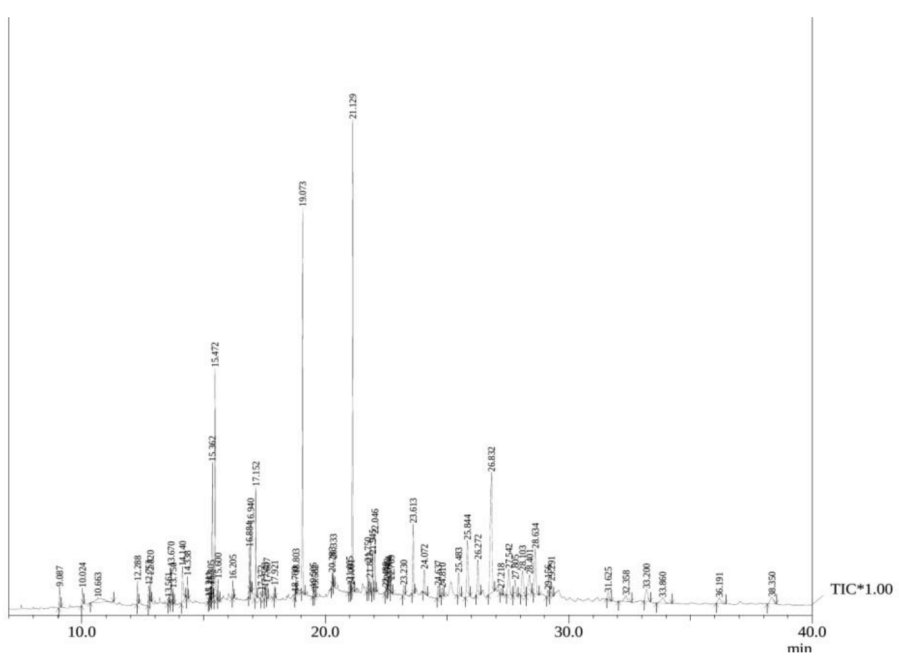

Figure 4: GC-MS chromatogram of ethyl acetate of $P$. latifolia methanolic extracts.

The presence of several biological active components in P. latifolia justifies traditional practitioners' use of it for a variety of diseases. However, the tedious task of isolating individual components and subjecting them to their biological activity will yield useful data. Finally, the results of the study show that $P$. latifolia contains a variety of biologically active components. As a result, this plant is indicated as a valuable therapeutic herb with pharmacological value.
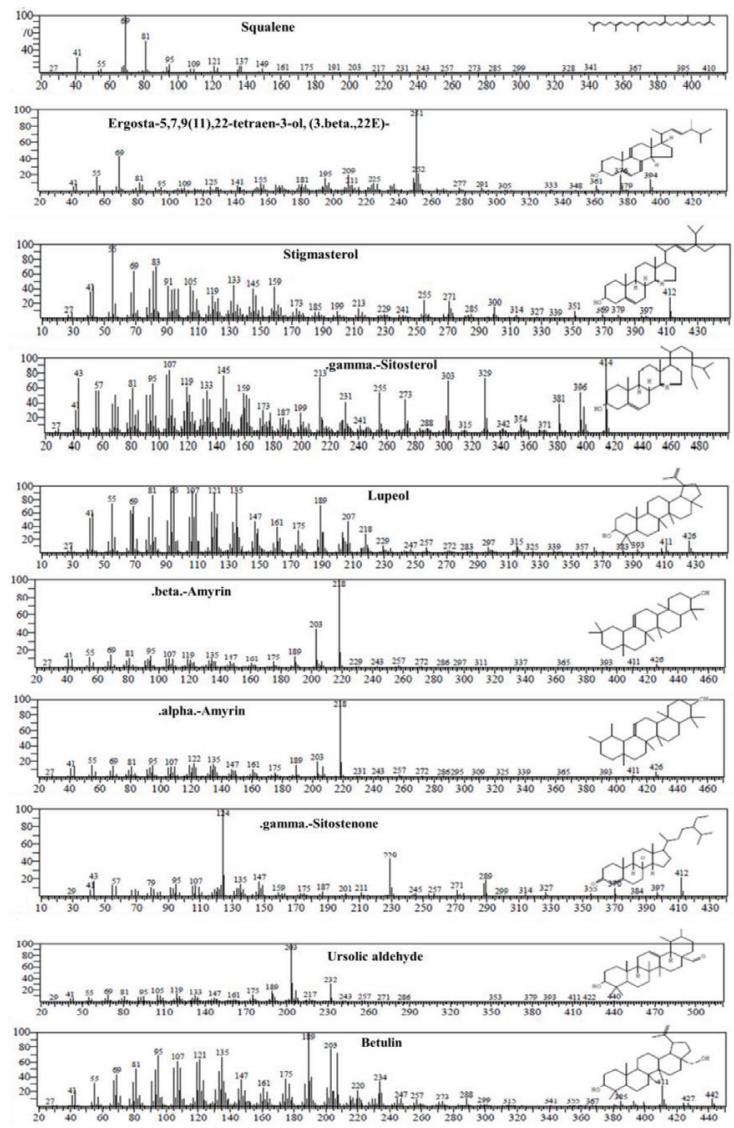

Figure 5: Mass spectrums of phyto-components identified by GC-MS in ethyl acetate fraction of methanolic extract of P. latifolia.
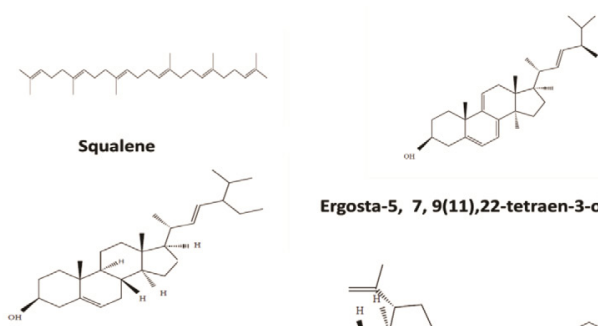

Ergosta-5, 7, 9(11),22-tetraen-3-ol,(3.beta.,22E)-

Stigmasteol

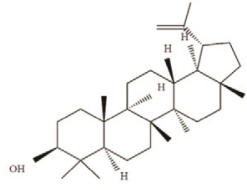

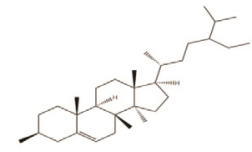

Lupeol

Gamma Sitosterol

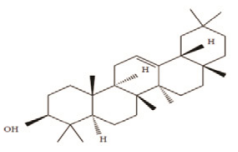

Beta-amyrin

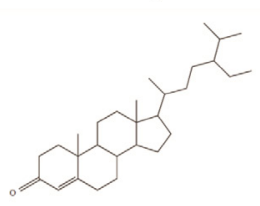

Gamma-Sitostenone

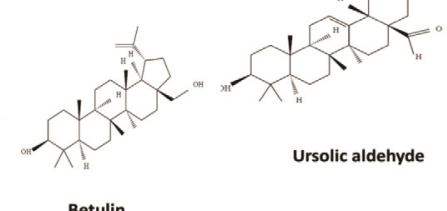

Figure 6: Structure of phytoconstituents obtained after GC-MS analysis. 
Table 1: Phyto-components identified in the methanolic extract of P. latifolia by GC-MS, MW: Molecular weight (g), RT: Retention Time.

\begin{tabular}{cccccc}
\hline No. & $\mathbf{R}_{T}$ & $\begin{array}{c}\text { Name of the } \\
\text { compound }\end{array}$ & $\begin{array}{c}\text { Molecular } \\
\text { formula }\end{array}$ & MW & $\begin{array}{c}\text { Peak area } \\
\%\end{array}$ \\
\hline 1. & 21.129 & Squalene & C30H50 & 410.7 & 13.57 \\
2. & 22.480 & $\begin{array}{c}\text { Ergosta-5,7,9(11), } \\
\text { 22-tetraen-3-ol, } \\
\text { (3.beta.,22E)- }\end{array}$ & C28H42O & 394.6 & 0.15 \\
3. & 25.844 & Stigmasterol & C29H48O & 412.7 & 3.73 \\
4. & 26.832 & .gamma.-Sitosterol & C29H50O & 414.7 & 10.13 \\
5. & 27.218 & Lupeol & C30H50O & 426.7 & 0.33 \\
6. & 27.542 & .beta.-Amyrin & C30H50O & 426.7 & 2.27 \\
7. & 28.401 & .alpha.-Amyrin & $\mathrm{C} 30 \mathrm{H} 50 \mathrm{O}$ & 426.7 & 2.05 \\
8. & 29.156 & .gamma.-Sitostenone & $\mathrm{C} 29 \mathrm{H} 48 \mathrm{O}$ & 412.7 & 0.35 \\
9. & 33.860 & Ursolic aldehyde & $\mathrm{C} 30 \mathrm{H} 48 \mathrm{O} 2$ & 440.7 & 1.01 \\
10 & 36.191 & Betulin & $\mathrm{C} 30 \mathrm{H} 50 \mathrm{O} 2$ & 442.8 & 0.72 \\
\hline
\end{tabular}

Table 2: Nature and biological activity of phyto-components identified in the methanolic extract of $P$. latifolia by GC-MS, RT: Retention Time

\begin{tabular}{|c|c|c|c|c|}
\hline No. & RT & $\begin{array}{l}\text { Name of the } \\
\text { compound }\end{array}$ & $\begin{array}{l}\text { Nature of } \\
\text { compound }\end{array}$ & Biological activity \\
\hline \multirow[t]{2}{*}{1.} & 21.129 & Squalene & Triterpene & $\begin{array}{l}\text { Skin emollient, } \\
\text { antioxidant }\end{array}$ \\
\hline & & & & Antitumor \\
\hline 2. & 22.480 & $\begin{array}{l}\text { Ergosta-5,7,9(11), } \\
\text { 22-tetraen-3-ol, } \\
\text { (3.beta.,22E)- }\end{array}$ & Phytosterol & Antitumor \\
\hline 3. & 25.844 & Stigmasterol & Steroid & Anti-osteoarthritic \\
\hline 4. & 26.832 & gamma.-Sitosterol & Phytosterol & Antidiabetic \\
\hline 5. & 27.218 & Lupeol & Triterpenoid & $\begin{array}{c}\text { Prostate and Skin } \\
\text { cancers, }\end{array}$ \\
\hline & & & & Anti-inflammatory \\
\hline 6. & 27.542 & beta.-Amyrin & Triterpene & $\begin{array}{c}\text { Analgesic, Anti } \\
\text { inflammatory, } \\
\text { Anticonvulsant, } \\
\text { Antidepressive, } \\
\text { Hepatoprotective, } \\
\text { Antihyperglycemic } \\
\text { Hypolipidemic }\end{array}$ \\
\hline 7. & 28.401 & .alpha.-Amyrin & Triterpenoid & $\begin{array}{l}\text { Anti-inflammatory, } \\
\text { Antinociceptive, } \\
\text { Antioxidant, } \\
\text { Antipruritic, } \\
\text { Gastroprotective }\end{array}$ \\
\hline 8. & 29.156 & $\begin{array}{l}\text {.gamma.- } \\
\text { Sitostenone }\end{array}$ & Phytosterol & \\
\hline 9. & 33.860 & Ursolic aldehyde & Triterpenoid & Anti-glycative \\
\hline 10 & 36.191 & Betulin & Triterpene & $\begin{array}{c}\text { Antimalarial, } \\
\text { Anti-inflammatory, } \\
\text { Antifungal }\end{array}$ \\
\hline
\end{tabular}

\section{ACKNOWLEDGEMENT}

This research was supported by UGC National Fellowship (Letter No. F1-17.1/2017-18/RGNF-2017-18-SC-HIM-28460/ (SA-III/Website).

\section{CONFLICT OF INTEREST}

The authors declare that there is no conflict of interest.

\section{ABBREVIATIONS}

MEPL: Methanol extract of Premna latifolia; TLC: Thin layer chromatography; HPTLC: High Pressure Thin Layer Chromatography; GCMS: Gas Chromatography mass; PLPE: (Premna latifolia, petroleum ether fraction); PLEA: (Premna latifolia, ethyl acetate fraction); PLAQ: Premna latifolia, aqueous fraction).

\section{REFERENCES}

1. Veeresham C (Dr. Natural products derived from plants as a source of drugs. J Adv Pharm Tech Res. 2012:3(4):200 doi: 10.4103/2231-4040.104709. Available from: /pmc/articles/PMC3560124

2. Petrovska BB. Historical review of medicinal plants' usage. Pharmacogn Rev. 2012;6(11):1-5. doi: 10.4103/0973-7847.95849, PMID 22654398. Available from: /pmc/articles/PMC3358962.

3. Pan SY, Litscher G, Gao SH, Zhou SF, Yu ZL, Chen HQ, et al. Historical perspective of traditional indigenous medical practices: the current renaissance and conservation of herbal resources. Evid Based Complement Alternat Med. 2014:2014:525340 doi: 10.1155/2014/525340, PMID 24872833. Available from: /pmc/articles/PMC4020364

4. Sasidharan S, Chen Y, Saravanan D, Sundram KM, Yoga Latha LY. Extraction, isolation and characterization of bioactive compounds from plants' extracts. Afr J Tradit Complement Altern Med. 2011;8(1):1-10. doi: 10.4314/ajtcam v8i1.60483, PMID 22238476. Available from: /pmc/articles/PMC3218439.

5. Abubakar AR, Haque M. Preparation of medicinal plants: basic extraction and fractionation procedures for experimental purposes. J Pharm Bioallied Sci. 2020:12(1):1-10. doi: 10.4103/jpbs.JPBS_175_19, PMID 32801594. Available from: /pmc/articles/PMC7398001

6. Atanasov AG, Waltenberger B, Pferschy-Wenzig EM, Linder T, Wawrosch $C$ Uhrin $P$, et al. Discovery and resupply of pharmacologically active plant-derived natural products: a review. Biotechnol Adv. 2015;33(8):1582-614. doi: 10.1016/j. biotechadv.2015.08.001, PMID 26281720. Available from:/pmc/articles/PMC4748402.

7. Dianita R, Jantan I. Ethnomedicinal uses, phytochemistry and pharmacological aspects of the genus Premna: a review. Pharm Biol. 2017;55(1):1715-39. doi: 10.1080/13880209.2017.1323225, PMID 28486830.

8. Kumari H, Shrikanth P, Chaithra PR, Pushpan R, Nishteswar K. A comparative experimental evaluation of anti-inflammatory activity of Premna obtusifolia Linn and Premna latifolia Roxb leaves in Charles foster rats. Anc Sci Life. 2011;31(2):58-61. PMID 23284207. Available from: /pmc/articles/PMC3530269.

9. Senguttuvan J, Paulsamy S, Karthika K. Phytochemical analysis and evaluation of leaf and root parts of the medicinal herb, Hypochaeris radicata $L$. for in vitro antioxidant activities. Asian Pac J Trop Biomed. 2014;4(Suppl 1):S359-67. doi: 10.12980/APJTB.4.2014C1030, PMID 25183112. Available from: /pmc/articles/ PMC4025295.

10. Reddy LH, Couvreur P. Squalene: A natural triterpene for use in disease management and therapy. Adv Drug Deliv Rev. 2009;61(15):1412-26. doi: 10.1016/j.addr.2009.09.005, PMID 19804806.

11. Huang ZR, Lin YK, Fang JY. Biological and pharmacological activities of squalene and related compounds: potential uses in cosmetic dermatology. Molecules. 2009;14(1):540-54. doi: 10.3390/molecules14010540, PMID 19169201. Available from: /pmc/articles/PMC6253993.

12. Singh B, Sharma RA. Plant terpenes: defense responses, phylogenetic analysis, regulation and clinical applications. 3 Biotech. 2015;5(2):129-51. doi: 10.1007/s13205-014-0220-2, PMID 28324581. Available from: /pmc/articles/ PMC4362742

13. Gabay O, Sanchez C, Salvat C, Chevy F, Breton M, Nourissat G, Wolf C Jacques C, Berenbaum F. Stigmasterol: A phytosterol with potential antiosteoarthritic properties. Osteoarthritis Cartilage. 2010;18(1):106-16. doi: 10.1016/j.joca.2009.08.019, PMID 19786147.

14. Torres S, Cajas D, Palfner G, Astuya A, Aballay A, Pérez C, Hernández V, Becerra J Steroidal composition and cytotoxic activity from fruiting body of Cortinarius xiphidipus. Nat Prod Res 2017;31(4):473-6. doi: 10.1080/14786419.2016.1185717. PMID 27198920.

15. Saleem M. Lupeol, A novel anti-inflammatory and anti-cancer dietary triterpene. Cancer Lett. 2009;285(2):109-15. doi: 10.1016/j.canlet.2009.04.033, PMID 19464787. Available from: /pmc/articles/PMC2764818.

16. NN O. Pharm Biol. 2014;52;DL(A), HN O, EE I, CS N, FB O. beta-Amyrin and 
alpha-amyrin acetate isolated from the stem bark of Alstonia boonei display profound anti-inflammatory activity:1478-86.

17. ZH W. CN H, MCY. Anti-glycative effects of oleanolic acid and ursolic acid in kidney of diabetic mice. Eur J Pharmacol. 2010;628;CC(H):255-60.
18. Alakurtti S, MäkeläT, Koskimies S, Yli-Kauhaluoma J. Pharmacological properties of the ubiquitous natural product betulin. Eur J Pharm Sci. 2006;29(1):1-13. doi: 10.1016/j.ejps.2006.04.006, PMID 16716572.

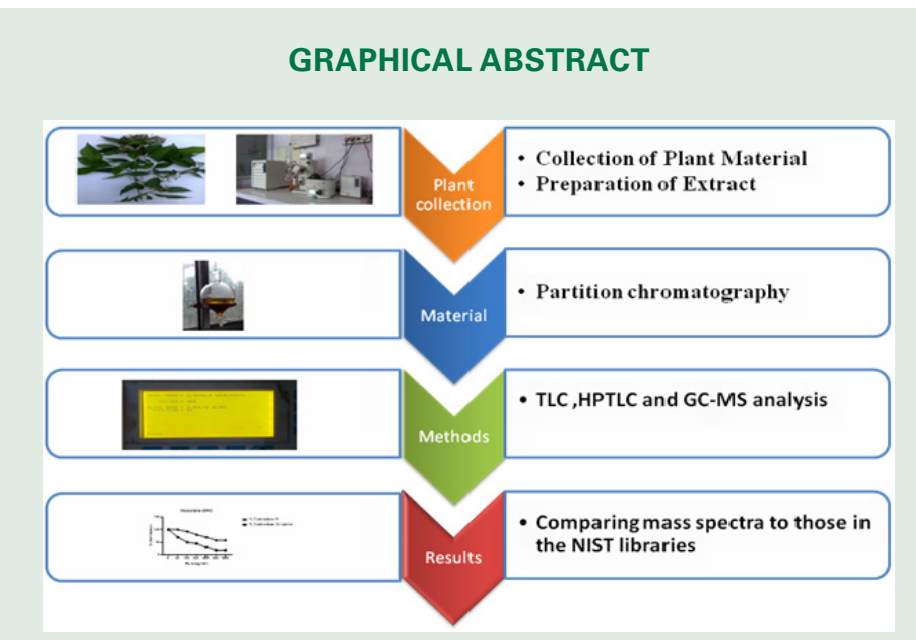

\section{SUMMARY}

The results obtained from phytochemical screening of Premna latifolia Roxb. identified the presence of glycosides, terpenoids, diterpenes and phenols. In GC-MS analysis; 66 different compounds with 10 major components Squalene (13.57 percent), Ergosta-5, 7, 9 (11), 22-tetraen-3-ol, (3. beta, 22E)-(0.15 percent), Stigmasterol (3.73 percent), gamma-Sitosterol (10.13 percent), Lupeol (0.33), beta-Amyrin (2.27 percent), alpha-Amyrin (2.05 percent), gamma-Sitostenone (0.35 percent), Ursolic aldehyde (1.01 percent) and Betulin (0.72 percent) were found. These compounds possess important biological activity and strongly support the pharmacological potency of Premna latifolia Roxb.

\section{ABOUT AUTHORS}

Prof Brijesh Kumar is working as faculty in Department of Pharmacology, Institute of Medical Sciences, Banaras Hindu University Varanasi, Uttar Pradesh, India.

Cite this article: Kumar R, Kumar B, Kumar A, Kumar A, Singh M. GC-MS analysis of Phytocomponents in the Methanol Extract of Premna latifolia Roxb. Pharmacog Res. 2022;14(1):19-23. 